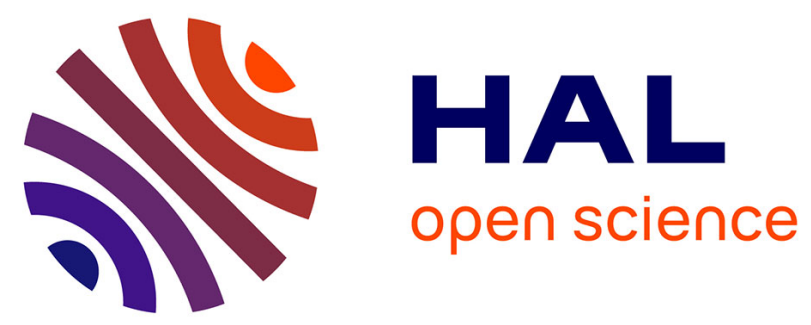

\title{
Modelling proportionate bud break in kiwifruit
}

D. Tisne Agostini, Simone Riolacci, Robert Habib

\section{To cite this version:}

D. Tisne Agostini, Simone Riolacci, Robert Habib. Modelling proportionate bud break in kiwifruit.

3. International Symposium, Feb 1992, Palmerston North, New Zealand. hal-02773215

\section{HAL Id: hal-02773215 \\ https://hal.inrae.fr/hal-02773215}

Submitted on 4 Jun 2020

HAL is a multi-disciplinary open access archive for the deposit and dissemination of scientific research documents, whether they are published or not. The documents may come from teaching and research institutions in France or abroad, or from public or private research centers.
L'archive ouverte pluridisciplinaire HAL, est destinée au dépôt et à la diffusion de documents scientifiques de niveau recherche, publiés ou non, émanant des établissements d'enseignement et de recherche français ou étrangers, des laboratoires publics ou privés. 
Number 313

October 1992

ISHS

International Society for Horticultural Science

\section{Third International Symposium on Computer Modelling in Fruit Research and Orchard Management}

Editors

J.G. Buwalda

T.A. Atkins

Palmerston North, New Zealand 11-14 February 1992 
D. Tisné-Agostini and S. Riolacci

INRA Station d'Agronomie

San Giuliano,

20230 San Nicolao

France

\author{
R. Habib \\ INRA Station d'Agronomie \\ Montfavet \\ 84143 Cedex \\ France
}

\section{Abstract}

The amount of budbreak in kiwifruit, is a major yield component. Its prediction could be useful to help growers during winter pruning. The influence of the amount of winter chilling on bud burst as well as the effect of spring temperatures on the final proportionate budbreak is known. In this paper a model for bud burst simulation is proposed according to spring temperatures. Hydrogen cyanamide treatments were used to increase variability in bud burst pattern. The model parameters and threshold value for temperature were then estimated by fitting the model to data. The model appears to be very suitable to describe between-treatment variability.

\section{Introduction}

The kiwifruit (Actinidia deliciosa cv Hayward) is a deciduous vine which bears fruits on the current season's shoots from buds developed in leaf axils from canes from the previous season (Brundell, 1975). As all winter buds along dormant canes are potentially reproductive (Grant et al., 1982), except for flatish buds borne at the base of the cane, the amount of budbreak is a major yield component.

Winter chilling is known to be important to terminate rest and enhance the amount of budbreak on Chinese gooseberry vines (Brundell, 1976 ; Lionakis et al., 1984a ; Lawes, 1984). However, Brundell (1976) also suggested that other factors in addition to low temperature might facilitate bud burst, as buds artificially chilled to $4^{\circ} \mathrm{C}$ do not resume growth as quickly as other naturally chilled buds. Among these factors, spring temperatures during budburst seem to be the most influential through concentration of the budbreak pattern. Lawes (1984) showed that the more concentrated the budbreak pattern, the higher the proportion of over-wintering buds that break. The same results were obtained by McPherson et al. (1990).

On a practical side, the prediction of proportionate budbreak could be very useful to help growers during winter pruning to produce the desired number of harvestable fruits. Doyle (1989) proposed a model predicting bud break according to the amount of cold temperatures during winter. But the influence of the prevailing temperature during budbreak was not taken into account. Of course, knowledge of spring temperature could not influence winter pruning or decisions regarding hydrogen cyanamid applications; however, it seems of interest to propose a model for budbreak simulation according to spring temperatures to better understand the physiology of bud burst. In addition it will at least practically help provide a guide to flower and fruitlet thinning.

\section{Material and methods}

The field experiment was performed in 1991 in a commercial orchard of Actinidia deliciosa cv Hayward in eastern Corsica (46 Gr 98 N, 7 Gr 98 E). 10-year-old vines issued from cuttings and T-bar trained were used. Over the experimental period the vines were managed using the normal winter pruning programme, i.e. 20 to 25 canes with approximately 20 buds each.

Acta Hórticulturae 313, 1992 
The aim of the experiment was to increase variability in budburst pattern by using a commercially available aqueous formulation of hydrogen cyanamide containing 490 g a.i. $1^{-1}$.

Whole vines were treated with 2 concentrations at 3 application dates and compared to an untreated control. They were sprayed with concentrations of 4 or 6 percent hydrogen cyanamide 55,45 or 37 days before theoretical bud burst : on 18 January, 28 January or 5 February. Treatment combinations and the untreated control were randomly allotted to three adjacent vine sub-plots within each of the four replicated blocks. Only the middle vine of each sub-plot was kept for observations.

Measurements and recordings were made on two canes from opposite sides of each treated vine. The canes selected were of average diameter and had not borne fruit in the previous year.

Nodes were numbered from the cane base to the tip and the date of bud burst was recorded individually. A bud was recorded as broken when it had swollen sufficiently to cause the bud cover to split open (Linsley-Noakes, 1989). The percentage of burst was calculated for each cane over time, so the bud burst pattern for each treatment and the untreated control could be determined.

Sheltered ambient air temperatures were monitored at a station located in the orchard. Hourly mean temperatures were recorded throughout the experimental period.

At the same time, the average state of dormancy of vines in the field was determined at fortnightly intervals using the method of isolated single-node cuttings (Mauget, 1976). The dormancy of isolated buds was measured by their growth ability, expressed as the time required for breaking on single node cuttings at $25^{\circ} \mathrm{C}$. The mean budburst time (MBT) is expressed in hours and represents the arithmetic mean of budburst time for individual buds. The higher the MBT, the more dormant the buds were considered to be.

\section{Modeling budburst response to high spring temperatures}

Among different possible models for describing bud burst pattern, a simple logistical function was selected whose the parameters may have a biological significance:

$\mathrm{Tx}=\mathrm{K} /\left[1+\exp \left(-\mathrm{a}\left(\mathrm{x}-\mathrm{x}_{\mathrm{i}}\right)\right)\right]$

where

Tx is proportionate budbreak

$\mathrm{x}$ is number of hours when the temperature is above a given threshold value

$\mathrm{K}$ is maximal proportionate budbreak

a is relative budbreak rate at the beginning of budbreak

$\mathrm{x}_{\mathrm{i}}$ is the value of $\mathrm{x}$ at maximum budbreak rate

It should be noted that the model gives final budbreak intensity as well as the delay for bud burst.

The model was fitted to data using the NLIN Procedure from the SAS package (1988). This method uses an iterative process where a starting value for the estimated value is chosen and continually improved until the error sum of squares is minimized. 
In the multivariate secant method (DUD), used here, the derivatives are estimated from the history of iterations and not supplied analytically.

\section{Results and discussion}

\subsection{Estimating the starting date for computing hours of temperature}

As proportionate budbreak is described as a function of time (number of hours above a given threshold value temperature), the starting date must be known. It was estimated to be 1st February from the figures showing the Mean Budburst Time (figure 1) and the Mean Budburst Percentage (MBP) (figure 2). The $I^{\text {st }}$ February is the date when MBP is the highest and MBT the lowest in the negative slope of dormancy release. This means that all the buds, when correlative inhibition has been suppressed, are no longer dormant and thus are able to growth if external conditions are favorable.

In the model, it is assumed that true dormancy release is achieved according to winter cold temperatures. After this time, it is supposed that only warm temperatures have an effect on budburst.

\subsection{Fitting the temperature threshold value}

In the model, the budbreak percentage is predicted from a number of hours when temperature is above a threshold value. Since some authors have shown the influence of a temperature of about $10^{\circ} \mathrm{C}$ on the growth ability of kiwifruit vines (Lionakis et al., $1984 \mathrm{~b}$; McPherson et al., 1990), six threshold values of temperature (NH7 to NH12) from $7^{\circ} \mathrm{C}$ to $12^{\circ} \mathrm{C}$ in $1^{\circ} \mathrm{C}$ increments were tested.

The choice of the most convenient threshold temperature value was performed statistically by fitting the model to the untreated control data set. The non-linear regression procedure from the SAS package was applied.

The temperature of $9^{\circ} \mathrm{C}$ was selected because it gave the lowest residual mean square (table 1).

From a biological aspect, this means that kiwifruit vines require rather high temperatures to resume growth compared to other fruit species (Morgan et al., 1985).

\subsection{Fitting the model parameters}

For each of the six Hydrogen Cyanamide treatments used to create variability in budburst patterns, proportionate budbreak was expressed as a function of number of hours above $9^{\circ} \mathrm{C}$. The model was fitted to each treatment data set. The same non-linear regression method was used (DUD) so that a set of three estimated parameters, $\mathrm{K}$, a and $x_{1}$ was obtained. Figure 3 shows the corresponding simulated curve for each treatment with the fitted parameters and actual proportionate budbreak values. In all cases variation in the data is significantly explained by the model as shown by a determination coefficient greater than 0.98. It appears that the measured bud burst pattern is well-described by the fitted pattern.

The parameters values were represented as histograms with confidence intervals for the six treatments and the untreated control (figure 4). For each parameter, K, A and $\mathrm{x}_{\mathrm{i}}$, the treatments are well differenciated. It is possible to rank the treatments in terms of their efficiency in function of the parameter values. There appears to be some interaction between concentration and application time. Except for the last application 
date, six percent hydrogen cyanamide was significantly higher than four percent in improving total bud burst intensity. The most successful application time appeared to be 8 weeks before natural bud break, which is much longer than in New Zealand (Linsley-Noakes, 1989).

The best results in terms of total budbreak amount were obtained with a treatment applied on 18 January 1991 with a $6 \%$ dilution, as shown by $K$ values for each treatment. The lower the relative budbreak rate at the beginning of bud burst, i.e. the significance of parameter "a", the more effective the hydrogen cyanamide application. In the same way, the smaller number of hours, at a temperature above $9^{\circ} \mathrm{C}$, for maximum budbreak rate, the better the efficiency of the treatment $\left(\mathrm{x}_{\mathfrak{j}}\right)$. variability.

The model thus appears to be very suitable to describe between-treatment

\section{$\underline{\text { 5. Conclusion }}$}

A simple logistical model of bud burst simulation according to spring temperatures has been fitted to data from a one-year experiment. It is shown to be efficient to describe budbreak variability induced by different hydrogen cyanamide applications.

\section{References}

Brundell, D.J., 1975. Quantitative aspects of flowering in the Chinese gooseberry (Actinidia chinensis Planch). New Zealand J. Agric. Res. 18:371-374.

Brundell, D.J., 1976. The effect of chilling on the termination of rest and flower bud development of the chinese gooseberry. Sci. Hort. 4:175-182.

Doyle, C.J., Moore, W.B., and Henzell, F., 1989. Modelling the economic consequences of potential management changes in a mature kiwifruit orchard in New Zealand. Agric. Systems 31:321-347.

Grant, J.A., and Ryugo K., 1982. Influence of developing shoots on flowering potential of dormant buds of Actinidia chinensis. HortScience 6:977-978.

Lawes, G.S., 1984. Winter temperatures and kiwifruit bud development. Orchardist New Zealand. 57:110.

Linsley-Noakes, G.C., 1989. Improving flowering of kiwifruit in climatically marginal areas using hydrogen cyanamide. Sci. Hort. 38:247-259.

Lionakis, S.M., and Schwabe, W.W., 1984a. Bud dormancy in the Kiwi fruit, Actinidia chinensis Planch. Ann. Bot. 54:467-484.

Lionakis, S.M., and Schwabe, W.W., 1984b. Some effects of daylenght, temperature and exogenous growth regulator application on the growth of Actinidia chinensis. Ann. Bot. 54:485-501.

Mauget, J. C., and Rageau, R., 1988. Bud dormancy and adaptation of apple tree to mild winter climates. Acta Hort. 232.

McPherson, H.G., Stanley, C.J., and Warrington, I.J., 1990. Winter and spring temperature effects on bud break and flowering in kiwifruit. XXIII International Horticultural Congress, Firenze.

Morgan, D.C., Warrington, I.J., and Halligan, E.A., 1985. Effect of temperature and photosynthetic photon flux density on vegetative growth of kiwifruit (Actinidia chinensis). New Zealand J. Agric. Res. 28:109-116.

SAS Institute Inc., 1988. SAS/STAT User's Guide, Release 6.03 Edition. Cary, NC:

SAS Institute Inc., $1028 \mathrm{pp}$. 
Table 1 - Estimation of parameters and residual mean square value for each threshold temperature value

\begin{tabular}{ccccc} 
& $\kappa$ & $a$ & $x_{i}$ & Aesiduad Mean Square \\
NH7 & 0.53 & 0.022 & +92 & 0.000314 \\
NHS & 0.53 & 0.027 & 412 & 0.000166 \\
\hline NH9 & 0.53 & 0.031 & 341 & 0.000154 \\
\hline NH10 & 0.53 & 0.035 & 279 & 0.000195 \\
NH11 & 0.53 & 0.042 & 203 & 0.000182 \\
NH12 & 0.54 & 0.063 & 106 & 0.000463
\end{tabular}

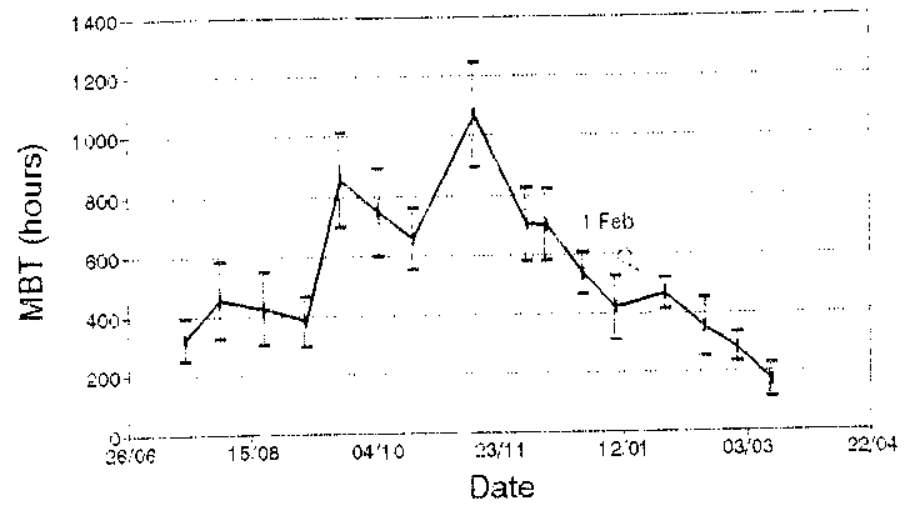

Figure 1 - Bud dormancy expressed by Mean Budburst Time in Actinidia deliosa cv Hayward.

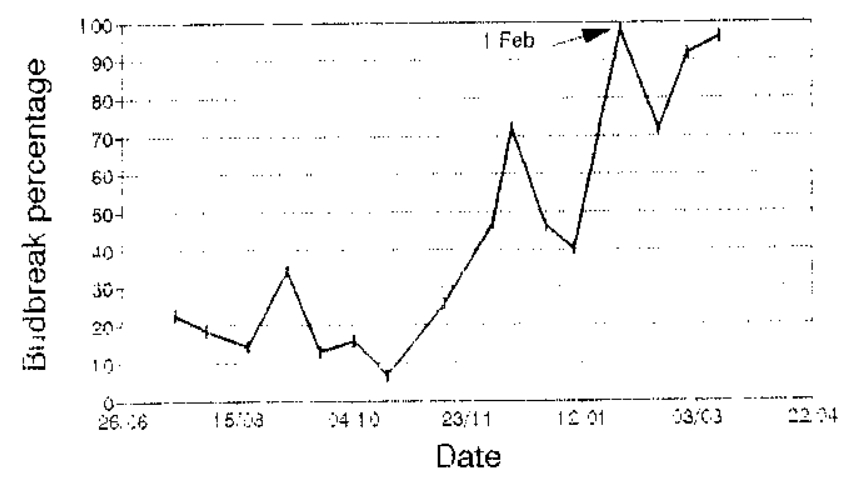

Figure 2 - Mean Budburst Percentage of isolated single-node cuttings 

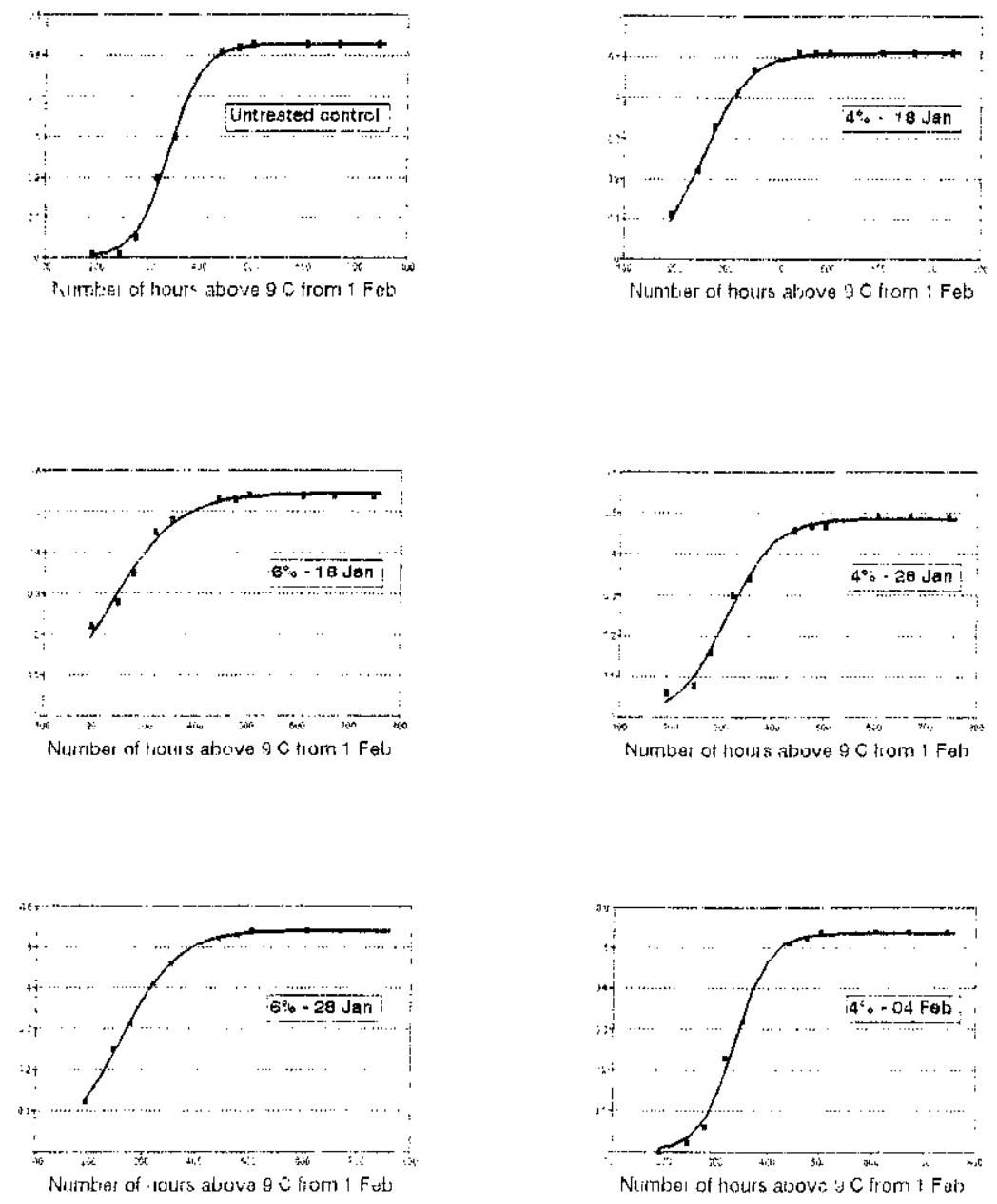

Figure 3 - Bud bieak pattern simulation and

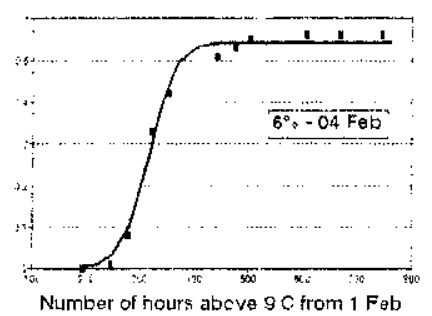
actual vaiues of proportionate hudburst for cach treatment, as a function of numbers of hours ahove $9 \mathrm{C}$ from 1 Fehruary. 

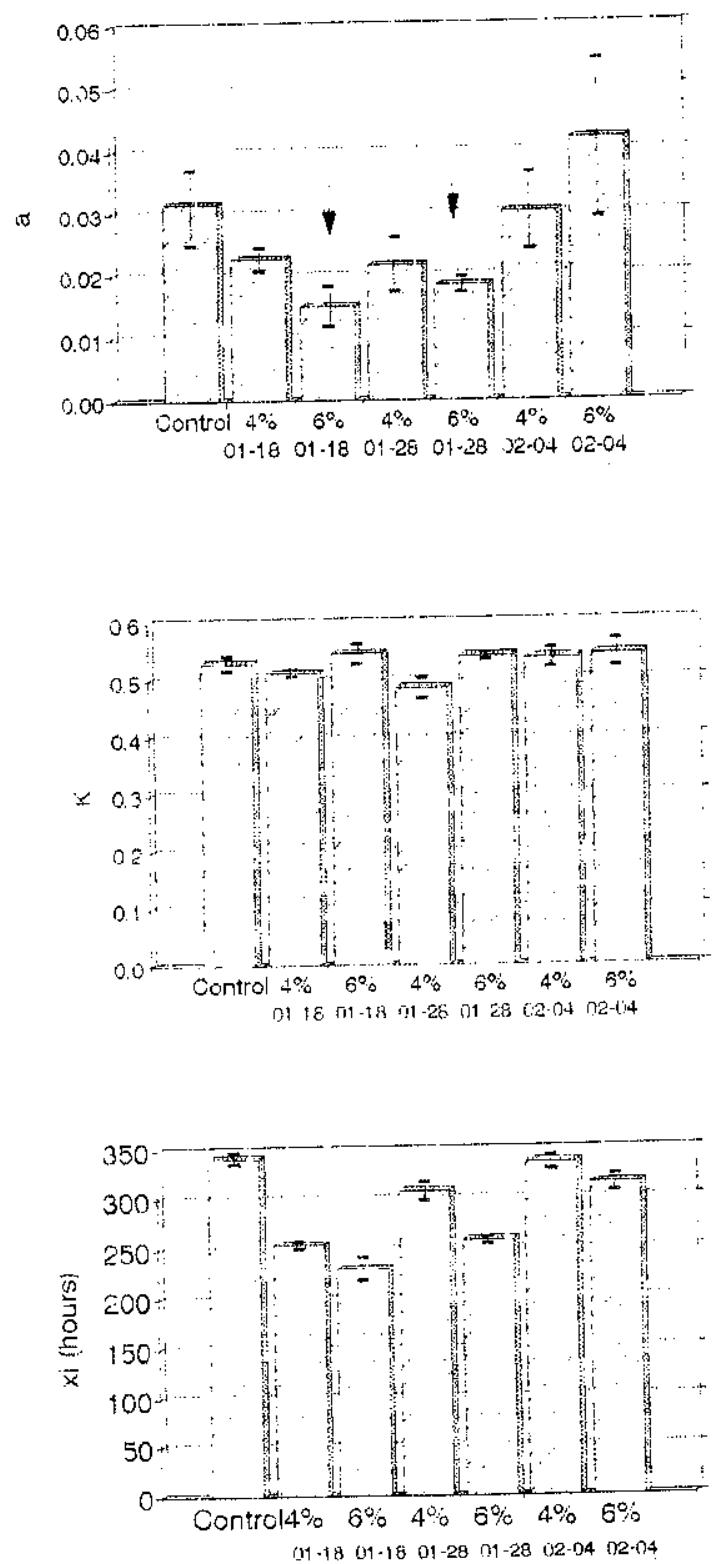

Figure + - Values of the model parameters for cach treatment ("a" for relative budbreak rate at the beginning of budbreak: "K" lor maximal proportionate budbreak: "xi" for the value of $x$ at maximum budbreak rates 